\title{
nature
}

\section{Albright's last scientific stand}

The US Secretary of State has announced some tentative steps towards the elusive goal of a scientifically literate State Department. Her successor will need to go further.

$\mathrm{S}$ cientific leaders in the United States have been whistling in the dark for many years now about the diminishing scientific and technical capabilities of the State Department, and were obviously relieved to hear Madeleine Albright, the Secretary of State, acknowledge their complaint directly in an address to the annual meeting of the American Association for the Advancement of Science (AAAS) last week.

The drumbeat of complaint about the scientific competence of the State Department has been driven by a rising number of scienceand technology-related issues, ranging from trade in genetically modified foods to the suspected proliferation of biological weapons, which confront today's diplomatic corps. In the United States this has coincided with a diminishing of that corps. In a report requested by the department, and delivered in preliminary form in 1998 and in its final form last year, the National Research Council (NRC) called for extensive remedial action.

"The State Department's scientific capabilities have not always been as substantial as they should be," said Albright to the AAAS. Her speech promised a policy statement on science, to appear this month, the appointment of a senior science adviser to the secretary (something mandated last autumn by the Congress) and the appointment of a science counsellor in New Delhi.

Beyond that, Albright had little concrete to offer. "This is not the time and place for an extended response to the NRC's report," the secretary said, leaving some of the audience wondering what would be a better time or place for such a response than aAAS meeting in Washington, more than a year after the bulk of the NRC's advice was delivered. The speech made no mention of the scientific advisory panel recommended by the NRC, or of its sensible suggestion that the State Department tap scientific expertise from other government agencies. It also hinted that no extra resources would be available from the State Department's existing budget to bolster its scientific expertise.

Despite the dearth of specifics in Albright's address, officials who have met with her say that she is genuinely committed to the rebirth of science at the State Department. But Albright's tenure is liable to end next January, with President Clinton's. That is one reason why scientific leaders have been working closely with the State Department's permanent bureaucracy to build support for reform. Optimists among them say that important civil servants now support the necessary change. They will need to do so strongly if the current momentum for reform is to survive the change of administration.

A task force inside the department is now drawing up a sciencepolicy document and, more importantly, an action plan to strengthen its scientific capabilities. The science adviser to the secretary will probably be appointed this summer, to serve out the closing months of the Clinton administration.

It will then fall to Albright's successor to implement the action plan. There is no guarantee that the vital but somewhat obscure issue of scientific competence will capture that person's attention. It took Albright 18 months to find time in her diary — early last month — for a meeting requested by Bruce Alberts, the president of the National Academy of Sciences; and Albright's engagement of this issue has occurred three years into her term of office. If her successor takes as long, last week's speech will be remembered less for its worthy sentiments than for its failure to announce meaningful action to update the State Department's approach to science and technology.

\section{A critical nuclear appointment}

The resignation of a chief executive poses a challenge for a profitable international company in desperate circumstances.

"W here science never sleeps" - so runs the catch-phrase of the public relations campaign for British Nuclear Fuels Limited (BNFL). And the science is extensive and challenging — instrumentation in hostile environments, technical evaluation of radioactive fuel inventories, Monte Carlo simulations for criticality safety margins and shielding, modelling of fuel elements in all possible conditions, magnetic technologies for separating particles in gases and levitated bearings, magnetohydrodynamics of glass vitrification, and much more. But some of the outcomes have been problematic: after years of delay before getting approval in 1994 to begin operations, the Thorp reprocessing centre has been severely hit by erosion and blockages in feeder lines.

Whatever the quality of the engineering, the management and culture at BNFL have been catastrophic for its reputation and for the profile of the nuclear industry as a whole. Important overseas customers in Japan and Germany have been outraged to discover falsified safety documentation. Investigating those scandals, the UK Nuclear Installations Inspectorate earlier this month condemned the company for its systematic management failures and lack of a safety culture.
BNFL is wholly owned by the UK government, which would

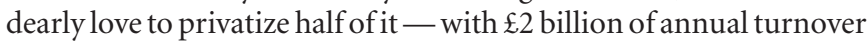
and profits running at about 10 per cent, it could be an attractive proposition under the right leadership. And it has a future: last year it bought Westinghouse, clinching its leading role in decommissioning and waste management in the United States and elsewhere, as well as supplying those countries in Asia still willing to invest in new nuclear plant.

In a recent study the Royal Society concluded that the nuclear option needed to be retained as other sources of energy run out or come under increasing question. But even if nuclear power is phased out altogether, its 'back end' will be with us for a long time. For those reasons, not only the board of BNFL but also the British government have a critical responsibility in the next few days or weeks in appointing a successor to replace John Taylor, the BNFL chief executive who resigned this week. That person will need grasp, acute sensitivity to the public interest, and a persona, to transform the culture and image of a business that will need constantly, in many countries, to demonstrate its absolute integrity, in both technical and moral senses. 